\title{
Effect of a glucosamine-based combination supplement containing chondroitin sulfate and antioxidant micronutrients in subjects with symptomatic knee osteoarthritis: A pilot study
}

\author{
YASUSHI NAKASONE ${ }^{1}$, KAZUNORI WATABE $^{1}$, KEITA WATANABE $^{2}$, AKIHITO TOMONAGA $^{3}$, \\ ISAO NAGAOKA $^{4}$, TETSURO YAMAMOTO ${ }^{5}$ and HIDEYO YAMAGUCHI ${ }^{5}$ \\ ${ }^{1}$ Kenkoukazoku, Inc., Kagoshima 892-0848; ${ }^{2}$ Kitashinyokohama Orthopedic Surgery, Kohoku-ku, Yokohama 223-0059; \\ ${ }^{3}$ Tana Orthopedic Surgery, Aoba-ku, Yokohama 227-0064; ${ }^{4}$ Department of Host Defense and Biochemical Research, \\ Juntendo University, Graduate School of Medicine, Bunkyo-ku, Tokyo 113-8421; \\ ${ }^{5}$ Research Center, TTC Co., Ltd., Shibuya-ku, Tokyo 150-0021, Japan
}

Received May 16, 2011; Accepted June 17, 2011

DOI: 10.3892/etm.2011.298

\begin{abstract}
In the present study, we aimed to investigate the potential effect of a glucosamine (1,200 mg/day)-based dietary supplement combined with chondroitin sulfate and three antioxidant micronutrients, namely methylsulfonylmethane, guava leaf extract, and vitamin D (test supplement) on osteoarthritis (OA) of the knee. A 16-week, randomized, double-blinded, placebo-controlled trial was conducted involving 32 subjects with symptomatic knee OA. Clinical outcomes were measured using the Japanese Knee Osteoarthritis Measure (JKOM) for symptoms and a study diary-based visual analog scale (diary VAS) for pain at baseline and at weeks 4, 8, 12 and 16 during the 16-week intervention period. Furthermore, biomarkers for cartilage type II collagen degradation (C2C) and synovitis hyaluronan (HA) were measured. As compared with the baseline, the JKOM pain subscale was significantly improved at all of the four assessment time points in the test group, but was not at any time point in the placebo group. On the other hand, all of the four symptom subscales and the aggregated total symptoms were significantly improved in the two groups at one or more time points. However, all of these clinical improvements were greater in extent in the test group than in the placebo group, and there were significant differences between groups in the magnitude of changes from baseline for one subscale 'general activities' and the aggregated total symptoms at week 8 $(\mathrm{P}<0.05)$. The results of efficacy assessments with the diary VAS showed that all of the three pain subscales were significantly improved only in the test group at almost all the time points. Moreover, serum levels of $\mathrm{C} 2 \mathrm{C}$ and HA were decreased
\end{abstract}

Correspondence to: Dr Hideyo Yamaguchi, Research Center, TTC Co., Ltd., 1-20-2 Ebisunishi, Shibuya-ku, Tokyo 150-0021, Japan

E-mail: h.yamaguchi@ttc-tokyo.co.jp

Key words: combination supplement, glucosamine, chondroitin sulfate, antioxidant micronutrients, joint tissue biomarkers, osteoarthritis by 10 and $25 \%$, respectively, at week 16 in the test group, albeit not statistically significant, without any detectable changes in the placebo group. In conclusion, although the results obtained in this study were not conclusive, the tested glucosamine-based combination supplement is likely to have a beneficial effect on pain and other symptoms associated with knee OA.

\section{Introduction}

Osteoarthritis (OA), which develops due to the progressive destruction of articular cartilage, is the most common joint disease and the leading cause of pain and physical disability in elderly people $(1,2)$. Moreover, as the proportion of elderly individuals in the population increases, the number of OA patients is expected to further increase. In OA, particularly knee joints are affected as they are weight-bearing joints. In Japan, similar to many other developed countries, the incidence and prevalence of knee OA are currently increasing with an increase in the elderly population (3). Thus, the management of knee OA, which requires extensive utilization of health care resources, has become a major social and economic issue in the health management of the elderly.

The mainstay of pharmacotherapeutic approaches to pain management in OA involves analgesics, nonsteroidal antiinflammatory drugs, selective cycloxygenase-2 inhibitors and an intra-articular injection of hyaluronan (HA) or corticosteroids. However, there are considerable data showing that these approaches frequently produce insufficient benefit with the associated risk of untoward side effects (4-7). It is, therefore, no wonder that patients with OA embrace complementary and alternative approaches to pain management of OA (8-12).

Orally administered glucosamine and chondroitin sulfate, used alone and in combination, both being natural components of articular cartilage, are extensively used as alternative medicines, and are suggested by several studies not only to reduce the OA-associated pain and other symptoms but also to suppress the disease progression $(13,14)$. However, contradictory data have also been reported in a fairly large number of studies, and thus the therapeutic efficacy of glucosamine and 
chondroitin sulfate alone and in combination is considered a controversial issue as described in several meta-analyses $(15,16)$ and a manuscript reporting the results of a more recently conducted large-scale clinical trial, the Glucosamine/ Chondroitin Arthritis Intervention Trial (GAIT) (17).

Besides glucosamine and chondroitin sulfate, several antioxidant micronutrients have also been reported to have the potential for relieving OA-associated pain and/or beneficially influencing osteoarthritic processes (18), probably through their analgesic, anti-inflammatory or antioxidative effects (19). The rationale is that inflammatory and oxidative damages due to over-production of nitric oxide and other reactive oxygen species (ROS) have been demonstrated in aging and osteoarthritic cartilage (20) and have been correlated with the extent of cartilage damage (21). This postulation is supported by the results of several laboratory studies demonstrating that chondrocytes are potent sources of ROS (22), and that ROS are implicated in the oxidative damage to cartilage and the development of OA $(23,24)$.

Based on these findings, we considered a glucosamine-based dietary supplement combined with chondroitin sulfate and three antioxidant micronutrients, namely methylsulfonylmethane (MSM), guava leaf extract and vitamin D, that is commercially available in Japan as a promising candidate nutraceutical for the management of knee OA. MSM is a natural substance present in various green plants, fruits and vegetables, and has been shown to modestly reduce pain and swelling in patients with knee OA when administered alone or in combination with glucosamine $(25,26)$. Guava leaf extract rich in quercetin and other polyphenols has anti-inflammatory and analgesic effects and is used as an antioxidant dietary supplement in Japan (27). Vitamin D has been reported to protect the development and to slow the progression of OA $(28,29)$.

The pathophysiological hallmark of OA is the focal destruction of articular cartilage, which results from increased degradation of cartilage matrix molecules including type II collagen (CII) and proteoglycans $(30,31)$. In this context, there is accumulating evidence suggesting that osteoarthritic processes may be beneficially modified by both glucosamine and chondroitin sulfate (32-36), and that their therapeutic effects could be evaluated by changes in the serum or urine levels of CII degradation biomarkers, such as CTX-II, C1, 2C and cartilage type II collagen degradation (C2C) (37-39). Moreover, in patients with several types of arthritis including OA, synthesis of HA was found to be enhanced in inflamed synovium or synovitis (40), eventually leading to an increase in serum levels of HA (41). Thus, although the primary objective of the present pilot study was to assess the clinical efficacy of the glucosamine-based combination supplement (test supplement) in subjects with symptomatic knee OA, its effect on biomarkers associated with CII metabolism and synovial inflammation was also investigated.

\section{Materials and methods}

Study design. A randomized, double-blinded, placebocontrolled study was designed to assess the efficacy and safety of the test supplement in adult subjects with symptomatic knee OA. The study was carried out from December 2009 to August 2010 and involved two clinical service organization centers in Yokohama, Japan. The study protocol was approved by the institutional ethics committee, and was conducted in accordance with the principles of the amended Declaration of Helsinki and 'Ethical Guidelines for Epidemiological Research (established by the Japanese Government in 2008)'. Written informed consent was obtained from all participants prior to their enrollment in the study. The overall design of the study consisted of a 16 -week intervention period preceded by an approximately 4-week run-in period. The subjects accomplished full clinical and laboratory examinations at baseline and at weeks 4, 8, 12 and 16 during the intervention period.

Subjects. Male and female Japanese subjects, aged 40-83 years with clinical and radiographic evidence of mild knee OA were enrolled; $30-75$ on a 100-mm visual analog scale (VAS) and radiological severity of affected knee joints mainly graded 1-2 on the Kellgren-Laurence (K/L) grade (42). Subjects with bilateral diagnosed knee OA were asked to specify the worse affected knee at baseline, and this knee was evaluated throughout the study period.

Exclusion criteria were: gout/hyperuricemia or rheumatic arthritis; prior knee surgery or its necessity; routine use of health foods containing glucosamine, chondroitin sulfate or any other constituents of the test supplement; known hypersensitivity or allergy to glucosamine or chondroitin sulfate; previous or current treatment with antiresorptive drugs such as bisphosphonates or estrogen; intra-articular injections of either corticosteroids (within the 3 previous months) or HA (within the previous 2 weeks) before the initiation of intervention; pregnant women, nursing mothers or women of child-bearing potential during the study period; participation in another clinical study; and the presence of any medical condition judged by the medical investigator to preclude the subject's inclusion in the study.

Intervention and subject assignment. The test supplement was a commercially available tablet-form preparation containing $1,200 \mathrm{mg}$ of glucosamine hydrochloride, $200 \mathrm{mg}$ of shark cartilage extract, of which approximately $30 \%$ (60 mg) is chondroitin sulfate, $300 \mathrm{mg}$ of MSM, $105 \mathrm{mg}$ of guava leaf extract and $5.6 \mu \mathrm{g}$ of vitamin $\mathrm{D}$, together with $7.35 \mathrm{mg}$ of vitamin $\mathrm{B}_{1}$ and vehicle (comprising lactose, maltitol and crystalline cellulose) at a daily dose of 7 tablets. Subjects were randomly assigned to receive 7 tablets $(2,300 \mathrm{mg})$ of the test supplement (test group), or 7 tablets $(2,300 \mathrm{mg}$ ) of dummy placebo containing only vehicle (placebo group). All subjects were instructed to take 7 tablets of the test supplement or placebo once daily at any time of the day. Intervention was continued for 16 weeks until the final visit (week 16). Adherence to the intervention was evaluated based on the consumption recorded in the study diary, and a value $<80 \%$ was considered a protocol violation.

Blood was obtained from subjects in a fasting state and second void of the morning urine was collected at every clinical visit. Aliquots of serum and urine samples were stored frozen until use for the blind-manner determination of OA-related biomarkers, whereas other aliquots of serum and urine samples were immediately used for the routine laboratory tests.

Efficacy assessment. Symptomatic changes over time during the intervention period were primarily assessed using the 
scores of the Japanese Knee Osteoarthritis Measure (JKOM) (43) developed by the Japanese Orthopaedic Association according to the concepts of the World Health Organization's International Classification of Functioning, Disability and Health 2001 (44) and in consideration of the specific Japanese cultural lifestyle, which differs somewhat from Western countries. The JKOM consists of subject pain rating based on a $100-\mathrm{mm}$ VAS and scores for a subscale of four symptoms based on a validated, disease-specific questionnaire addressing four dimensions: 'pain/stiffness', 'condition in daily life', 'general conditions' and 'health conditions', with $8,10,5$ and 2 questions, respectively (43). Each question is rated on an ordinal scale of $0-4$, with higher scores indicating a symptom or medical condition of higher severity. The four symptom subscales can be scored separately or combined to represent the aggregated total symptoms. It was previously demonstrated by a Japanese Orthopaedic Research Group that the JKOM is reliable and valid for studies of clinical outcomes for Japanese patients with knee OA (45).

Pain in the target knee was also measured using three pain subscales of the study diary-based visual analog scale for pain (diary VAS): 'pain at rest', 'pain on walking' and 'pain on ascending/descending stairs'. Each pain subscale was scored from 0 to 100 , where 0 indicates no pain and 100 indicates the worst pain thus far experienced. Scores for these three pain subscales were recorded every day at home throughout the intervention period and were separately used as outcome measurements.

C2C and HA were utilized to assess the effect of the test supplement on cartilage metabolism and synovial inflammation, respectively. Serum levels of C2C and HA were measured using Collagen Type II Cleavage ELISA (IBEX Pharmaceuticals, Inc.) and LPIA-ACE HA (Mitsubishi Chemical Medience Corp.), respectively.

Data on all of the outcome measurements were collected at baseline and at weeks 4, 8, 12 and 16 during the 16-week intervention period (except for the biomarker measurements at week 4), and the within-group comparison of the mean values and the between-group comparison of the mean changes from the baseline were carried out.

Safety assessment. Safety was assessed throughout the study on the basis of the incidence and severity of intervention-related adverse events (side effects) as well as abnormal changes in blood pressure, pulse rate and laboratory tests, which included hematology, biochemical profile and urinalysis.

Statistical analysis. Values were expressed as mean \pm standard deviation (SD) unless otherwise specified. Baseline data of the subjects were compared between the test and placebo groups using the unpaired Student's t-test for continuous variables and by the Mann-Whitney U test for category variables. Symptomatic scores and biomarker levels during the intervention were compared to the baseline values using the paired Student's t-test (for quantitative variables) and the Wilcoxon's signed rank test (for qualitative variables). Comparisons between the two groups were performed using the unpaired Student's t-test (for qualitative variables) and the MannWhitney U test (for qualitative variables). P-values $<0.05$ were considered statistically significant.

\section{Results}

Baseline characteristics. Data from 32 subjects who fulfilled the eligibility criteria and completed the study, were analyzed for clinical efficacy and safety. As shown in Table I, the demographic characteristics (age, male/female ratio) and physiological characteristics (height, body weight, body mass index, systolic/diastolic blood pressures, pulse rate) were not different between the test and placebo groups. Similarly, scores for the pain subscale and individual scores for all of the four symptom subscales, as well as scores for the aggregated total symptoms, of the JKOM were almost balanced between the two groups. In contrast, scores for the two diary VAS pain subscales, 'pain on walking' and 'pain on ascending/descending stairs', were significantly higher in the test group than in the placebo group $(\mathrm{P}<0.05)$. Moreover, another diary VAS pain subscale 'pain at rest' and the serum levels of both $\mathrm{C} 2 \mathrm{C}$ and HA were slightly higher in the test group than in the placebo group, although the differences were not significant. Adherence to the allotted dietary supplement (test supplement or placebo) exceeded $85 \%$ in all of the 32 subjects (16 each in the two groups), and no subject discontinued the study.

Clinical efficacy. Table II shows the changes over time in scores for the pain subscale and individual scores for all of the four symptom subscales, together with scores for the aggregated total symptoms, of the JKOM during the 16-week intervention period. The pain subscale scores decreased time-dependently and reached a significant level at weeks 8, 12 and 16 compared with the baseline $(\mathrm{P}<0.05)$ in the test group, whereas no such significant changes were noted at any time points in the placebo group. In respect to the JKOM symptom subscales, individual scores for three of the four subscales, namely 'pain/ stiffness', 'condition in daily life', and 'general activities', as well as scores for the aggregated total symptoms, were all significantly improved at weeks 8,12 and 16 compared with baseline in the test group $(\mathrm{P}<0.01$ each), although improvements in scores for the subscale 'health conditions' were lower in extent, reaching a significant level only at week 16 $(\mathrm{P}<0.05)$. Significant decreases in individual scores for the three subscales, 'pain/stiffness', 'condition in daily life', and 'general activities', and scores for the aggregated total symptoms were also noted in the placebo group $(\mathrm{P}<0.05$ each). However, the magnitude of changes from baseline in scores for these symptom subscales and the aggregated total symptoms were all greater in the test group than in the placebo group. In particular at week 8 , significant differences between the test and placebo groups were noted in scores for the 'general activities' $(-2.7 \pm 2.3$ vs. $-0.9 \pm 1.9 ; \mathrm{P}<0.05)$ and in scores for the aggregated total symptoms $(-13.0 \pm 8.9$ vs. $-5.0 \pm 10 ; \mathrm{P}<0.05)$.

Table III shows the changes in scores for the three diary VAS pain subscales, 'pain at rest', 'pain on walking' and 'pain on ascending/descending stairs', in the two groups during the 16 -week intervention. Scores for all of the three subscales significantly decreased from baseline at almost all of the four assessment time points (weeks 4, 8, 12 and 16) in the test group $(\mathrm{P}<0.05$ each), whereas none of the subscale scores showed a significant decrease at any time point in the placebo group. Moreover, the magnitude of score reductions from baseline appeared greater at all of the time points in the test group than 
Table I. Baseline data of subjects in the test and placebo groups who completed the study .

\begin{tabular}{|c|c|c|}
\hline Baseline variables & Test group $(n=16)$ & Placebo group $(n=16)$ \\
\hline Age (years) & $56.4 \pm 7.7$ & $54.5 \pm 9.1$ \\
\hline Male/female (no. of subjects) & $2 / 14$ & $2 / 14$ \\
\hline Height $(\mathrm{cm})$ & $156.9 \pm 6.8$ & $157.1 \pm 7.7$ \\
\hline Weight (kg) & $59.8 \pm 6.1$ & $55.8 \pm 10.2$ \\
\hline Body mass index $\left(\mathrm{kg} / \mathrm{m}^{2}\right)$ & $24.4 \pm 2.9$ & $22.6 \pm 3.9$ \\
\hline Systolic blood pressure (mmHg) & $128.1 \pm 18.1$ & $125.6 \pm 14.5$ \\
\hline Diastolic blood pressure (mmHg) & $80.4 \pm 9.8$ & $76.9 \pm 8.9$ \\
\hline Pulse rate (beats/min) & $62.6 \pm 6.9$ & $63.7 \pm 6.1$ \\
\hline JKOM, VAS pain subscale scores (mm) & $53.3 \pm 14.4$ & $47.2 \pm 15.2$ \\
\hline \multicolumn{3}{|l|}{ JKOM, symptom subscale scores } \\
\hline Pain/stiffness & $20.9 \pm 4.2$ & $18.7 \pm 4.9$ \\
\hline Condition in daily life & $19.4 \pm 4.8$ & $17.2 \pm 5.6$ \\
\hline General activities & $11.0 \pm 3.5$ & $9.3 \pm 2.6$ \\
\hline Health conditions & $4.6 \pm 1.3$ & $4.1 \pm 1.2$ \\
\hline Aggregated total symptoms & $53.3 \pm 14.4$ & $47.2 \pm 15.2$ \\
\hline \multicolumn{3}{|l|}{ Diary VAS pain subscale scores (mm) } \\
\hline Pain at rest & $31.1 \pm 27.2$ & $16.3 \pm 21.2$ \\
\hline Pain on walking & $59.0 \pm 14.9^{b}$ & $43.3 \pm 20.7$ \\
\hline Pain on ascending/descending stairs & $66.2 \pm 13.3^{b}$ & $51.3 \pm 22.5$ \\
\hline Kellgren-Laurence grades, 1-2 (\%) & 94 & 88 \\
\hline Serum C2C (ng/ml) & $212.0 \pm 39.6$ & $188.8 \pm 33.7$ \\
\hline Serum HA (ng/ml) & $46.5 \pm 42.1$ & $26.6 \pm 12.3$ \\
\hline
\end{tabular}

${ }^{a}$ All values are expressed as the mean $\pm \mathrm{SD}$ except for 'male/female' and 'Kellgren-Laurence grades'. ' $\mathrm{P}<0.05$ according to the unpaired Student's t-test (comparison between the two groups).

Table II. Changes in mean JKOM scores for VAS pain, the individual four symptom subscales and the aggregated total symptoms during the 16-week intervention period in the test and placebo groups $(n=16$ each).

\begin{tabular}{|c|c|c|c|c|c|c|}
\hline \multirow[b]{2}{*}{ Subscale } & \multirow[b]{2}{*}{ Group } & \multicolumn{5}{|c|}{ Scores at ${ }^{\mathrm{a}}$} \\
\hline & & Baseline & Week 4 & Week 8 & Week 12 & Week 16 \\
\hline \multirow[t]{2}{*}{ VAS pain } & Test & $53.3 \pm 14.4$ & $44.9 \pm 16.8$ & $32.2 \pm 19.1^{\mathrm{c}}$ & $29.8 \pm 21.2^{c}$ & $22.6 \pm 22.9^{b}$ \\
\hline & Placebo & $47.2 \pm 15.2$ & $43.4 \pm 15.9$ & $36.9 \pm 20.9$ & $25.2 \pm 22.3$ & $20.0 \pm 25.0$ \\
\hline \multirow[t]{2}{*}{ Pain/stiffness } & Test & $20.9 \pm 4.2$ & $17.3 \pm 2.8^{c}$ & $15.8 \pm 3.5^{\mathrm{c}}$ & $16.0 \pm 4.3^{\mathrm{c}}$ & $13.4 \pm 4.0^{\mathrm{c}}$ \\
\hline & Placebo & $18.7 \pm 4.9$ & $16.8 \pm 5.4$ & $16.8 \pm 5.9$ & $15.2 \pm 5.9^{c}$ & $14.3 \pm 5.6^{c}$ \\
\hline \multirow[t]{2}{*}{ Condition in daily life } & Test & $19.4 \pm 4.8$ & $16.1 \pm 3.1^{\mathrm{c}}$ & $14.4 \pm 2.4^{\mathrm{c}}$ & $14.8 \pm 5.6^{\mathrm{c}}$ & $13.5 \pm 3.9^{\mathrm{c}}$ \\
\hline & Placebo & $17.2 \pm 5.6$ & $15.6 \pm 5.6$ & $15.1 \pm 5.6^{\mathrm{b}}$ & $13.7 \pm 5.3^{c}$ & $13.3 \pm 4.9^{\mathrm{c}}$ \\
\hline \multirow[t]{2}{*}{ General activities } & Test & $11.0 \pm 3.5$ & $8.3 \pm 2.1^{\mathrm{c}}$ & $8.3 \pm 2.1^{\mathrm{c}}$ & $8.8 \pm 3.7^{c}$ & $8.2 \pm 2.8^{c}$ \\
\hline & Placebo & $9.3 \pm 2.6$ & $8.1 \pm 2.1^{\mathrm{b}}$ & $8.4 \pm 3.2$ & $7.9 \pm 2.4^{\mathrm{b}}$ & $7.8 \pm 2.8^{\mathrm{b}}$ \\
\hline \multirow[t]{2}{*}{ Health conditions } & Test & $4.6 \pm 1.3$ & $4.2 \pm 0.8$ & $4.4 \pm 1.1$ & $4.1 \pm 1.2$ & $3.7 \pm 1.2^{\mathrm{b}}$ \\
\hline & Placebo & $4.1 \pm 1.2$ & $4.3 \pm 1.4$ & $4.0 \pm 1.0$ & $3.6 \pm 1.0$ & $3.7 \pm 1.6$ \\
\hline \multirow[t]{2}{*}{ Aggregated total symptoms } & Test & $55.9 \pm 10.9$ & $45.9 \pm 5.3^{c}$ & $42.9 \pm 5.8^{c}$ & $43.6 \pm 12.7^{c}$ & $38.8 \pm 13.2^{\mathrm{c}}$ \\
\hline & Placebo & $49.3 \pm 12.4$ & $44.8 \pm 11.8$ & $44.3 \pm 14.0^{\mathrm{b}}$ & $40.4 \pm 13.0^{c}$ & $39.0 \pm 13.2^{\mathrm{c}}$ \\
\hline
\end{tabular}

${ }^{\mathrm{a}}$ Values are expressed as the mean $\pm \mathrm{SD} .{ }^{\mathrm{b}} \mathrm{P}<0.05,{ }^{\mathrm{c}} \mathrm{P}<0.01$ against baseline (paired Student's t-test). 
Table III. Changes in mean scores for the three diary VAS pain subscales during the 16-week intervention period in the test and placebo groups $(n=16$ each).

\begin{tabular}{|c|c|c|c|c|c|c|}
\hline \multirow[b]{2}{*}{ Subscale } & \multirow[b]{2}{*}{ Group } & \multicolumn{5}{|c|}{ Scores at ${ }^{\mathrm{a}}$} \\
\hline & & Baseline & Week 4 & Week 8 & Week 12 & Week 16 \\
\hline \multirow[t]{2}{*}{ Pain at rest } & Test & $31.1 \pm 27.1$ & $14.9 \pm 15.6^{\mathrm{a}}$ & $15.6 \pm 19.0$ & $15.7 \pm 19.3^{\mathrm{a}}$ & $12.3 \pm 22.1^{\mathrm{a}}$ \\
\hline & Placebo & $16.3 \pm 21.2$ & $12.4 \pm 16.6$ & $12.2 \pm 14.5$ & $10.6 \pm 16.8$ & $13.1 \pm 25.2$ \\
\hline \multirow[t]{2}{*}{ Pain on walking } & Test & $59.0 \pm 14.9$ & $34.1 \pm 19.3^{\mathrm{b}}$ & $27.4 \pm 19.6^{\mathrm{b}}$ & $26.6 \pm 21.7^{\mathrm{b}}$ & $17.7 \pm 19.8^{b}$ \\
\hline & Placebo & $43.3 \pm 20.7$ & $34.9 \pm 24.6$ & $29.9 \pm 21.8$ & $22.1 \pm 28.6$ & $21.9 \pm 32.5$ \\
\hline \multirow{2}{*}{$\begin{array}{l}\text { Pain on ascending/ } \\
\text { descending stairs }\end{array}$} & Test & $66.2 \pm 13.3$ & $44.2 \pm 16.8^{\mathrm{b}}$ & $30.7 \pm 20.8^{b}$ & $31.5 \pm 24.1^{\mathrm{b}}$ & $24.7 \pm 25.1^{\mathrm{b}}$ \\
\hline & Placebo & $51.3 \pm 22.5$ & $45.1 \pm 26.9$ & $34.6 \pm 25.9$ & $26.5 \pm 29.9$ & $24.4 \pm 32.4$ \\
\hline
\end{tabular}

${ }^{\mathrm{a}}$ Values are expressed as the mean $\pm \mathrm{SD} .{ }^{\mathrm{b}} \mathrm{P}<0.05,{ }^{\mathrm{c}} \mathrm{P}<0.01$ against baseline (paired Student's t-test).

Table IV. Changes in mean serum levels of a CII degradation biomarker C2C and a synovitis biomarker HA during the 16-week intervention period in the test and placebo groups $(n=16$ each).

\begin{tabular}{|c|c|c|c|c|c|}
\hline \multirow[b]{2}{*}{ Biomarker } & \multirow[b]{2}{*}{ Group } & \multicolumn{4}{|c|}{ Mean values $(\mathrm{ng} / \mathrm{ml}) \mathrm{at}^{\mathrm{a}}$} \\
\hline & & Baseline & Week 8 & Week 12 & Week 16 \\
\hline \multirow[t]{2}{*}{$\mathrm{C} 2 \mathrm{C}$} & Test & $212.0 \pm 39.6$ & $196.8 \pm 21.0(-7)$ & $198.2 \pm 27.7(-7)$ & $190.3 \pm 35.8(10)$ \\
\hline & Placebo & $188.8 \pm 33.7$ & $193.3 \pm 25.2(2)$ & $200.4 \pm 29.3(6)$ & $198.1 \pm 31.0(5)$ \\
\hline \multirow[t]{2}{*}{ HA } & Test & $46.5 \pm 42.1$ & $36.4 \pm 24.8(-12)$ & $35.6 \pm 19.7(-23)$ & $35.1 \pm 26.2(-25)$ \\
\hline & Placebo & $26.6 \pm 12.3$ & $29.0 \pm 12.5(9)$ & $28.3 \pm 10.2(6)$ & $28.0 \pm 13.9(5)$ \\
\hline
\end{tabular}

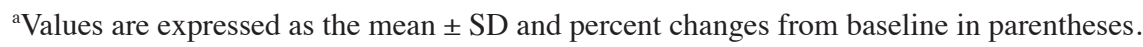

in the placebo group; differences in scores for 'pain on walking' between the test and the placebo group at week $8(-31.6 \pm 22.4$ vs. $-13.4 \pm 30.5)$ and those at week $16(-41.3 \pm 20.5$ vs. $-21.4 \pm 30.5)$ achieved a statistical significance $(\mathrm{P}<0.05$ each $)$.

Effect on biomarkers. As shown in Table IV, the serum levels of $\mathrm{C} 2 \mathrm{C}$ and $\mathrm{HA}$ were substantially reduced during the intervention period at weeks 8, 12 and 16 in the test group, although the extent of changes were not statistically significant. In the placebo group, in contrast, $\mathrm{C} 2 \mathrm{C}$ levels rather increased and HA levels were virtually unchanged throughout the intervention periodin the placebo group. Notably, the differences in the magnitude of reduction from baseline between the test and placebo groups were significantly larger in the former group than in the latter for C2C levels at week $12(-13.8 \pm 30.6$ vs. $11.6 \pm 35.4 \mathrm{ng} / \mathrm{ml})$ and those for HA at week $8(-10.1 \pm 20.6$ vs. $2.4 \pm 11.7 \mathrm{ng} / \mathrm{ml})$, both achieving a statistical significance $(\mathrm{P}<0.05$ each).

Safety. Eight subjects (50\%) in the test group and 6 subjects $(38 \%)$ in the placebo group reported at least one interventionassociated adverse event. None of subjects in the two groups discontinued the intervention for the reasons of adverse events. Adverse events most frequently reported from both the test and placebo subjects were respiratory symptoms (asthma, sore throat, cough, rhinorrhea, malaise and/or fever) and pain (hip, tooth or head). All adverse events were of mild intensity and were judged by the medical investigator as unrelated to the intervention. In both groups, routine laboratory tests and measurements of physiological parameters (body weight, body mass index, blood pressures and pulse rate) did not show any significant abnormalities throughout the intervention.

\section{Discussion}

In this pilot randomized, double-blinded, placebo-controlled trial, the tested glucosamine-based combination supplement containing chondroitin sulfate and three antioxidant micronutrients was primarily evaluated for its clinical efficacy in subjects with mild knee OA (K/L grades mainly 1-2). Efficacy of the test supplement for pain relief in knee OA subjects was basically supported by data indicating significant reduction from baseline in scores for the JKOM pain subscale and scales for the diary VAS pain subscales at almost all of the four assessment time points (weeks 4,8,12 and 16) in the test group compared to the placebo group. Moreover, individual scores for the four JKOM symptom subscales, as well as scores for the aggregated total symptoms, which are primarily related to knee OA-associated general symptoms, physical functions and health-related quality of life, were also significantly improved from baseline in the test group. However, when comparing the magnitude of changes in scores from baseline between the two groups, significant improvements were observed only 
in scores for the 'general activities' subscale and the aggregated total symptoms of the JKOM at week 8 and scores for the 'pain on walking' subscale of the diary VAS at weeks 8 and 16 . The discrepancy in the significance in the withinand between-group differences may be partly explained by previous findings that a strong placebo effect is observed in many OA clinical studies conducted for relatively short intervention periods $(46,47)$. Thus, although there were substantial limitations to clearly assess the therapeutic efficacy of the test supplement in the present study, the results of the JKOM- and dairy VAS-based efficacy assessments strongly suggest that the test supplement is potentially effective in improving pain and other symptoms associated with knee OA.

In connection with the possible symptomatic efficacy, glucosamine and chondroitin sulfate have been reported to reduce the osteoarthritic joint damage and to slow the progression of OA $(13,14,48)$. Recently, various biomarkers have been developed to detect the articular alterations in OA $(49,50)$, and there are accumulating data supporting the association of the changes in various CII degradation biomarkers, such as CTX-II, $\mathrm{C} 1,2 \mathrm{C}$ and $\mathrm{C} 2 \mathrm{C}$ (51-53), and a synovial inflammation biomarker HA $(54,55)$ with the disease progression in knee OA. In the present study, we utilized $\mathrm{C} 2 \mathrm{C}$ and $\mathrm{HA}$ for evaluating the effects of the test supplement on the pathophysiological changes in the cartilage and synovium, respectively, as described previously (56). The results demonstrated that the serum levels of both $\mathrm{C} 2 \mathrm{C}$ and HA time-dependently decreased only in the test group. This observation suggests that the test supplement may suppress the CII degradation and synovial inflammation in osteoarthritic joints, thereby possibly reducing cartilage loss and inflammatory responses. Along with the CII degradation in the articular cartilage by collagenases, persistent synovitis, as reflected by the increased serum HA levels, has been shown to predict the disease process of OA $(54,57)$. These findings lead us to the speculation that substantial antioxidant activities of the micronutrients which were contained in the test supplement may be effective in not only preventing the activation of collagenases by ROS (58) but also protecting HA molecules in the synovial fluid from degradation by ROS (59). This could partly explain the reduction in the serum levels of $\mathrm{C} 2 \mathrm{C}$ and $\mathrm{HA}$ noted in the $\mathrm{OA}$ subjects treated with the test supplement. It appears, therefore, likely that such pathophysiologically favorable effects of the test supplement on the osteoarthritic joint tissues may be involved in its therapeutic efficacy in subjects with knee OA.

The present pilot clinical study has some limitations. First, the number of subjects enrolled in both the test and placebo groups was small, which may have decreased the power to detect significant difference between the two groups. Second, as we did not use antioxidant micronutrient-free control dietary supplements, we were unable to learn the role of specific antioxidant components of the test supplement in its therapeutic efficacy. Extended larger studies are necessary to assess the potential of this combination supplement for improving clinical symptoms, as well as for preventing cartilage loss and/or suppressing synovial inflammation, in subjects with knee OA.

\section{Acknowledgements}

We would like to thank Mrs. Kaori Yoshimura for her statistical expertise and help in the preparation of the manuscript.

\section{References}

1. Ravenda V, Manette C, Lemmens R, Mariani AM, Struvay N and Reginster JY: Prevalence and impact of osteoarthritis and osteoporosis on health-related quality of life among active subjects. Aging Clin Exp Res 19: 55-60, 2007.

2. Jinks C, Jordan K and Croft P: Osteoarthritis as a public health problem: the impact of developing knee pain on physical function in adults living in the community: (KNEST 3). Rheumatology (Oxford) 46: 877-881, 2007.

3. Yoshimura N, Muraki S, Oka H, Mabuchi A, En-Yo Y, Yoshida M, Saika A, Yoshida H, Suzuki T, Yamamoto S, Ishibashi H, Kawaguchi H, Nakamura K and Akune T: Prevalence of knee osteoarthritis, lumbar spondylosis, and osteoporosis in Japanese men and women: the research on osteoarthritis/osteoporosis against disability study. J Bone Miner Metab 27: 620-628, 2009.

4. Eccles M, Freemantle N and Mason J: North of England evidencebased guidelines development project: summary guidelines for non-steroidal anti-inflammatory drugs versus basic analgesia in treating the pain of degenerative arthritis. North of England Non-steroidal Anti-inflammatory Drug Guidelines Development Group. BMJ 317: 526-530, 1998.

5. Wieland HA, Michaelis M, Kirschbaum BJ and Rudolphi KA: Osteoarthritis: an untreatable disease? Nat Rev Drug Discov 4: 331-344, 2005.

6. Rashad S, Revell P, Hemingway A, Low F, Rainford K and Walker F: Effect of non-steroidal anti-inflammatory drugs on the course of osteoarthritis. Lancet 2: 519-522, 1989.

7. Adams ME, Lussier AJ and Peyron JG: A risk-benefit assessment of injections of hyaluronan and its derivatives in the treatment of knee osteoarthritis. Drug Saf 23: 115-130, 2000.

8. Eisenberg DM, Davis RB, Ettner SL, Appel S, Wilkey S, Van Rompay M and Kessler RC: Trends in alternative medicine use in the United States, 1990-1997: results of a follow-up national survey. JAMA 280: 1569-1575, 1998.

9. Rao JK, Mihaliak K, Kroenke K, Bradley J, Tiemey WM and Weinberger M: Use of complementary therapies for arthritis among patients of rheumatologists. Am Intern Med 131: 409-416, 1999.

10. Astin JA: Why patients use alternative medicine: results of a national study. JAMA 279: 1548-1553, 1998.

11. Bellamy N and Buchanan WW: Outcome measurement in osteoarthritis clinical trials: the case for standardization. Clin Rheumatol 3: 293-305, 1984.

12. Lequesne M, Brandt K, Bellamy N, Moskowitz R, Menkes CJ, Pelletier JP and Altman R: Guidelines for testing slow acting drugs in osteoarthritis. J Rheumatol Suppl 41: 65-71, 1994.

13. Pavelká K, Gatterová J, Olejarová M, Machacek S, Giacovelli G and Rovati LC: Glucosamine sulfate use and delay of progression of knee osteoarthritis. A 3-year, randomized, placebo-controlled, double-blind study. Arch Intern Med 162: 2113-2123, 2002.

14. Reginster JY, Deroisy R, Rovati LC, Lee RL, Lejeune E, Bruyere O, Giacovelli G, Henrotin Y, Dacre JE and Gossett C: Long-term effects of glucosamine sulfate on osteoarthritis progression: a randomised, placebo-controlled clinical trial. Lancet 357: 251-256, 2001.

15. McAlindon TE, La Valley MP, Gulin JP and Felson DT: Glucosamine and chondroitin for treatment of osteoarthritis: a systematic quality assessment and meta-analysis. JAMA 283: 1469-1475, 2000.

16. Richy F, Bruyere O, Ethgen O, Cucherat M, Henrotin Y and Reginster JY: Structural and symptomatic efficacy of glucosamine and chondroitin sulfate in knee osteoarthritis. A comprehensive meta-analysis. Arch Intern Med 163: 1514-1522, 2003.

17. Clegg DO, Reda DJ, Harris CL, Klein MA, O'Dell JR, Hooper MM, Bradley JD, Bingham CO III, Weisman MH, Jackson CG, Lane NE, Cush JJ, Moreland LW, Schumacher HR Jr, Oddis CV, Wolfe F, Molitor JA, Yocum DE, Schnitzer TJ, Furst DE, Sawitzke AD, Shi H, Brandt KD, Moskowitz RW and Williams HJ: Glucosamine, chondroitin sulfate and the two in combination for painful knee osteoarthritis. N Engl J Med 354: 795-808, 2006

18. Natural Medicines Comprehensive Database. 8th edition. Therapeutic Research Faculty, Stockton, CA, 2006. http://www. naturaldatabase.com. (Accessed April 21, 2011).

19. Rosenbaum CC, O'Mathúna DP, Chavez M and Shields K: Antioxidants and anti-inflammatory dietary supplements for osteoarthritis and rheumatoid arthritis. Altern Ther Health Med 16: 32-40, 2010. 
20. Loeser RF, Carlson CS, Del Carlo M and Cole A: Detection of nitrotyrosine in aging and osteoarthritic cartilage: correlation of oxidative damage with the presence of interleukin-1 beta and with chondrocyte resistance to insulin-like growth factor 1. Arthritis Rheum 46: 2349-2357, 2002.

21. Yudoh K, Nguyen T, Nakamura H, Hongo-Masuko K, Kato T and Nishioka K: Potential involvement of oxidative stress in cartilage senescence and development of osteoarthritis: oxidative stress induces chondrocyte telomere instability and down-regulation of chondrocyte function. Arthritis Res Ther 7: R380-R391, 2005.

22. Henrotin Y, Deby-Dupont G, Deby C, De Bruyn M, Lamy M and Franchimont P: Production of active oxygen species by isolated human chondrocytes. Br J Rheumatol 32: 562-567, 1993.

23. Henrotin Y, Deby-Dupont G, Deby C, Franchimont P and Emerit I: Active oxygen species, articular inflammation and cartilage damage. EXS 62: 308-322, 1992.

24. Martin JA and Buckwalter JA: Aging, articular cartilage chondrocyte senescence and osteoarthritis. Biogerontology 3 : 257-264, 2002

25. Usha PR and Naidu MU: Randomised, double-blind, parallel, placebo-controlled study of oral glucosamine, methylsulfonylmethane and their combination in osteoarthritis. Clin Drug Invest 24: 353-363, 2004

26. Kim LS, Axelrod LJ, Howard P, Buratovich N and Waters RF Efficacy of methylsulfonylmethane (MSM) in osteoarthritis pain of the knee: a pilot clinical trial. Osteoarthritis Cartilage 14: 286-294, 2006

27. Ojewole JA: Antiinflammatory and analgesic effects of Psidium guajava Linn. (Myrtaceae) leaf acqueous extract in rats and mice. Methods Find Exp Clin Pharmacol 28: 441-446, 2006.

28. McAlindon TE, Jaques P, Zhang Y, Hannan MT, Aliabadi P, Weissman B, Rush D, Levy D and Felson DT: Do antioxidant micronutrients protect against the development and progression of knee osteoarthritis? Arthritis Rheum 39: 648-656, 1996.

29. McAlindon TE, Felson DT, Zhang Y, Hannan MT, Aliabadi P Weissman B, Rush D, Wilson PW and Jacques P: Relation of dietary intake and serum levels of vitamin $D$ to progression of osteoarthritis of the knee among participants in the Framingham Study. Ann Intern Med 125: 353-359, 1996.

30. Rizkalla G, Reiner A, Bogoch E and Poole AR: Studies on the articular cartilage proteoglycan aggrecan in health and osteoarthritis. Evidence for molecular heterogeneity and extensive molecular changes in disease. J Clin Invest 90: 2268-2277, 1992.

31. Poole AR, Kobayashi M, Yasuda T, Laverty S, Mwale F, Kojima T, Sakai T, Wahl C, El-Maadaway S, Webb G, Tchetina E and Wu W: Type II collagen degradation and its regulation in articular cartilage in osteoarthritis. Ann Rheum Dis 61 (Suppl 2): S78-S81, 2002.

32. Bassleer C, Ravati L and Frachimont P: Stimulation of proteoglycan production by glucosamine sulfate in chondrocytes isolated from human osteoarthritic articular cartilage in vitro. Osteoarthritis Cartilage 6: 427-434, 1998

33. Piperno M, Reboul P, Hellio Le Graverand MP, Peschard MJ, Annefeld M, Richard M and Vignon E: Glucosamine sulfate modulates dysregulated activities of human osteoarthritic chondrocytes in vitro. Osteoarthritis Cartilage 8: 207-212, 2000.

34. Lipiello L, Woodward J, Karpman R and Hammand TA: In vivo chondroprotection and metabolic synergy of glucosamine and chondroitin sulfate. Clin Orthop Relat Res 381: 229-240, 2000.

35. Oegema TR, Deloria LB, Sandy JD and Hart DA: Effect of oral glucosamine on cartilage and meniscus in normal and chymopapain-injected knee of young rabbits. Arthritis Rheum 46: 2495-2503, 2002.

36. Uebelhart D, Thonar EJ, Zhang J and Williams JM: Protective effect of exogenous chondroitin 4,6-sulfate in the acute degradation of articular cartilage in the rabbit. Osteoarthritis Cartilage 6 (Suppl 1): S6-S13, 1998.

37. Christgau S, Henrotin Y, Tankó LB, Rovati LC, Collette J, Bruyere O, Deroisy R and Reginster JY: Osteoarthritic patients with high cartilage turnover show increased responsiveness to the cartilage protecting effects of glucosamine sulfate. Clin Exp Rheumatol 22: 36-42, 2004.

38. Cibere J, Thorne A, Kopec JA, Singer J, Canvin J, Robinson DB, Pope J, Grant E, Lobanok T, Ionescu M, Poole AR and Esdaile JM: Glucosamine sulfate and cartilage type II collagen degradation in patients with knee osteoarthritis: randomized discontinuation trial results employing biomarkers. J Rheumatol 32: 896-902, 2005.

39. Mazières B, Hucher M, Zaïm M and Garnero P: Effect of chondroitin sulfate in symptomatic knee osteoarthritis: a multicentre, randomized, double-blind, placebo-controlled study. Ann Rheum Dis 66: 639-645, 2007.
40. Wells AF, Klareskog L, Lindblad S and Laurent TC: Correlation between increased hyaluronan localized in arthritic synovium and the presence of proliferating cells: a role for macrophagederived factors. Arthritis Rheum 35: 391-396, 1992.

41. Vilim V, Vytásek R, Olejárová M, Machácek S, Gatterová J, Procházka B, Kraus VB and Pavelka K: Serum cartilage oligomeric matrix protein reflects the presence of clinically diagnosed synovitis in patients with knee osteoarthritis. Osteoarthritis Cartilage 9: 612-618, 2001

42. Kellgren JH and Lawrence JS: Radiological assessment of osteoarthritis. Ann Rheum Dis 16: 494-502, 1957.

43. Akai M, Doi T, Fujino K, Iwaya T, Kurosawa H and Nasu T: An outcome measure for Japanese people with knee osteoarthritis. J Rheumatol 32: 1524-1532, 2005 .

44. International Classification of Functioning, Disability and Health. World Health Organization, Geneva, 2001.

45. Akai M, Iwaya T, Kurosawa H, Doi T, Nasu T, Hayashi K and Fujino K: Development of new disease-specific QOL measure for patients with knee osteoarthritis. Japanese Knee Osteoarthritis Measure (JKOM). J Phys Med 16: 55-62, 2005.

46. Lewis B, Lewis D and Cumming G: The comparative analgesic efficacy of transcutaneous electric nerve stimulation and a nonsteroidal anti-inflammatory drug for painful osteoarthritis. Br J Rheumatol 33: 455-460, 1994.

47. Pham T, Van der Heijde D, Lassere M, Altman RD, Anderson JJ, Bellamy N, Hochberg M, Simon L, Strand V, Woodworth T and Dougados M; OMERACT-OARSI: Outcome variables for osteoarthritis clinical trial: the OMERACT-OARSI set of responder criteria. J Rheumatol 30: 1648-1654, 2003.

48. Michel BA, Stucki G, Frey D, De Vathaire F, Vignon E, Bruehlmann P and Uebelhart D: Chondroitins 4 and 6 sulphate in osteoarthritis of the knee: a randomized, controlled trial. Arthiritis Rheum 52: 779-786, 2005.

49. Garnero P and Delmas PD: Biomarkers in osteoarthritis. Curr Opin Rheumatol 15: 641-646, 2003

50. Kraus VB: Biomarkers in osteoarthritis. Curr Opin Rheumatol 17: 641-646, 2005.

51. Garnero P, Ayral X, Rousseau FC, Christgau S, Sandell LJ, Dougados $\mathrm{M}$ and Delmas PD: Uncoupling of type II collagen synthesis and degradation predicts progression of joint damage in patients with knee osteoarthritis. Arthritis Rheum 46: 2613-2624, 2002.

52. Reijman M,Hazes JM, Bierma-Zeinstra SM, Koes BW, Christgau S, Christiansen C, Uitterlinden AG and Pols HA: A new marker for osteoarthritis: cross-sectional and longitudinal approach. Arthritis Rheum 50: 2471-2478, 2004

53. Poole AR, Ionescu M, Fitzcharles MA and Billinghurst RC: The assessment of cartilage degradation in vivo: development of an immunoassay for the measurement in body fluids of type II collagen cleaved by collagenases. J Immunol Methods 294: 145-153, 2004.

54. Sharif M, George E, Shepstone L, Knudson W, Thonar EJ, Cushnaghan J and Dieppe P: Serum hyaluronic acid level as a predictor of disease progression in osteoarthritis of the knee. Arthritis Rheum 38: 760-767, 1995.

55. Pavelka K, Forejtová S, Olejárová M, Gatterová J, Senolt L, Spacek P, Braun M, Hulejová M, Stovicková J and Pavelková A: Hyaluronic acid levels may have predictive value for the progression of knee osteoarthritis. Osteoarthritis Cartilage 12: 277-283, 2004

56. Mazières B, Garnero P, Guéguen A, Abbal M, Berdah L, Lequesne M, Nguyen M, Sallles JP, Vignon E and Dougados M: Molecular markers of cartilage breakdown and synovitis at baseline as predictors of structural progression of hip osteoarthritis. The ECHODIAH Cohort. Ann Rheum Dis 65: 354-359, 2006.

57. Ayral X, Pickering EH, Woodworth TG, Mackillop N and Dougados M: Synovitis: a potential predictive factor of structural progression of medial tibiofemoral knee osteoarthritis - results of a 1 year longitudinal arthroscopic study in 422 patients. Osteoarthritis Cartilage 13: 361-367, 2005.

58. Saari H, Sorsa T, Lindy O, Sumalainen K, Halinen S and Konttinen YT: Reactive oxygen species as regulators of human neutrophil and fibroblast interstitial collagenases. Int J Tissue React 14: 113-120, 1992.

59. Saari H, Konttinen YT, Friman C and Sorsa T: Differential effects of reactive oxygen species on native synovial fluid and purified human umbrical cord hyaluronate. Inflammation 17: $403-415,1993$. 